\title{
AS DIVERSAS ESCALAS DE ANÁLISE DO ESPAÇO METROPOLITANO: O ESPAÇO INTRAURBANO E INTRA-METROPOLITANO
}

\author{
THE VARIOUS ANALYSIS SCALES OF METROPOLITAN SPACE: THE URBAN AND METROPOLITAN SPACE \\ LAS DIVERSAS ESCALAS DE ANÁLISIS DEL ESPACIO METROPOLITANO: EL ESPACIO URBANO Y \\ METROPOLITANO \\ José Vandério Cirqueira Pinto - SME - Goiânia - Goiás \\ vanderio@hotmail.com
}

\begin{abstract}
Resumo
As recentes análises urbanas apontam para o problema da expansão urbana generalizada e das suas diversas denominações. Com o interesse de classificar as diferentes formas e funções desses aglomerados urbanos, distintos estudos utilizam várias nomeações, como: cidades mundiais, megacidades, metrópoles, megalópoles, metápolis, cidade-região, entre outras. Essas denominações demonstram o quanto as cidades apresentam possibilidades de interpretações que utilizem o recurso de diversas escalas. Considerar as várias escalas de análise, além de classificar e dar nomes às cidades, tem como proposta reconhecer as múltiplas dimensões espaciais contidas na cidade.
\end{abstract}

Palavras-chave: Escalas urbanas. Intraurbano. Intra-metropolitano.

\begin{abstract}
The recents urban analyses poit to the problem of the widespread urban expansion and of various denominations its. With the interest to classify the different ways and functions of these urban concentrations, different studies use various denominations like: world cities, metropolis, region-city and others. These denominations show that the cities present possibilities of interpretations that use the resort of various scales. To consider the various analusis scales, besides to classify and to give names to the cities, it hás like proposal to recognize the multiple space dimensions contained in the city.
\end{abstract}

Key words: Urban scales. Urban space. Metropolitan space.

\section{Resumen}

Las recientes análisis urbanas apuntan para el problema de la expansión urbana generalizada y de las suyas diversas denominaciones. Con el interes de clasificar las diferentes formas y funciones de eses aglomerados urbanos, distintos estudos utilizan diversas denominaciones entre ellas: ciudades mundiales, metrópolis, ciudad-región, entre otras. Esas denominaciones demostran que las ciudades presentan posibles análisis que utilizan el recurso de diversas escalas. Considerar las diversas escalas de análisis, allende clasificar y dar nombres a las ciudades, tiene como propuesta reconocer las diversas dimensiones espaciales contenidas em la ciudad.

Palabras claves: Escalas urbanas. Espacio urbano. Espacio metropolitano. 


\section{Introdução}

Contudo, a realização prática da urbanidade passa pela existência de vários lugares tão interrelacionados quanto possível, a fim de que tudo ocorra como se eles constituíssem um único lugar. A técnica mais eficaz para tornar a mobilidade supérflua se encontra justamente na própria mobilidade. A urbanização é, por princípio, portadora de um crescimento das mobilidades intra-urbanas. (LEVY, 2002, p. 2)

O espaço urbano é passível de diversas interpretações quando é considerado a possibilidade de se utilizar do recurso do recorte espacial e temporal, garantido por sua vez, pela escala. Considerar as distintas escalas de análises presentes no espaço urbano é ampliar as condições de investigações mais universalizantes e ao mesmo tempo mais localizantes de um determinado recorte espacial.

A multiplicidade das escalas espaciais se sustenta na mobilidade. Esta garante as interrelações dos lugares, unificando-os em um mesmo espaço. Com a mobilidade quebra-se a rigidez dos estratos espaciais demarcados pelas escalas.

O que garante a integração das escalas urbanas é a mobilidade em seu estado efetivo. Essa virtualidade espacial proporciona movimentações urbanas, que por sua vez redesenham novas configurações espaciais, cada vez mais complexas e mais integradas. As interações espaciais acionadas pela flexibilidade das escalas promovem alterações na escala do tempo urbano, não somente na escala espacial.

Com o crescimento e desenvolvimento das cidades atuais a questão da escala urbana torna-se cada vez mais considerável, e necessária, para que se compreenda a problemática metropolitana instaurada. A vivência dos sujeitos urbanos depende, indiscriminadamente, da mobilidade entre as escalas da cidade. Utilizar-se de distintas escalas para o entendimento do espaço urbano proporciona a análise de várias cidades em uma só, e de diversas configurações espaciais, em decorrência da exigência de apuradas visualizações e interpretações do meio urbano.

\section{O desenvolvimento urbano e o crescimento urbano: uma questão de escala}

Desenvolvimento urbano não é o simples crescimento das cidades ou a formação de uma rede urbana. Clark (1985) discute que crescimento urbano é apenas a expansão e estruturação do tecido urbano, seguido obviamen- 
te do acréscimo populacional, dos processos de conurbação e periferização. Já a urbanização, está ligada às mudanças no modo de vida dos citadinos, na alteração cultural do cidadão, no consumo, na moradia e com relação às complexas redes de relações evoluídas na metrópole moderna. Para Clark (1985, p. 62) a urbanização é

[...] um processo social e não espacial que se refere às mudanças nas relações comportamentais e sociais que ocorrem na sociedade, como resultado de pessoas morando em cidade. Essencialmente isso refere-se às mudanças complexas no estilo de vida, que decorrem do impacto das cidades sobre a sociedade.

Na contramão das terminologias de Clark (1985), Beaujeu-Garnier (1980, p. 24) mostra que o termo urbanização está ligado ao crescimento populacional, e civilização urbana refere-se "a penetração parcial dos hábitos, e dos modos de vida da cidade, no mundo rural”. Conforme classificou a autora, o acréscimo populacional gera a formação de uma região urbanizada. Já a formação da rede urbana ou as transformações na qualidade dos modos de vida dos citadinos estão ligadas à configuração da região urbana.

Apesar de divergentes, os dois autores concordam que o desenvolvimento urbano motiva as transformações nos modos de vida dos habitantes. Mas o que eles não consideraram, e o que torna frágil a análise dos mesmos, é que o espaço urbano não deve ser somente classificado por terminologias, o que levaria a tautologias. Não basta só diferenciar conceitos. É preciso mostrar as diferenças significativas na materialidade socioespacial que os termos anunciam.

Em contrapartida, Souza (2005) tece comentários acerca da ideologia do conceito de desenvolvimento urbano. Para este autor, a palavra desenvolvimento urbano lembra desenvolvimento econômico ou desenvolvimento sustentável. Mas Souza (2005) recusa essa posição reducionista de usar o conceito de desenvolvimento, pois o desenvolvimento econômico nada mais é do que maximização de lucros, ou o aumento da capacidade de uma sociedade de produzir mais. É necessário que o desenvolvimento seja encarado como um meio de desenvolver condições que melhore a qualidade de vida e a justiça social, atingindo melhores oportunidades para a sociedade, reduzindo iniquidades, promovendo o bem comum, e não se limitando ao crescimento de taxas de evolução econômica, pois aí está a ideologia do desenvolvimento urbano. Com relação a esse assunto Souza (2005, p. 19) argumenta: 
No entanto, sob a guarita de uma certa ideologia do desenvolvimento, ainda hoje hegemônica, privilegia-se, na conceituação de desenvolvimento, exatamente sua dimensão econômica, levando a que se entronize um conceito que se define antes pelos meios, mediante os quais se pode aprimorar o modelo social capitalista, do que pelos fins que, de um ponto de vista social geral, deveriam nortear e dar concretude à expressão mudança para melhor.

Conforme foi destacado, existe uma dimensão política embutida no desenvolvimento urbano. Castells (2000) denunciou que existe por trás dos interesses de planificação urbana, reurbanização e melhoria na qualidade de vida da sociedade uma ideologia urbana. Essa ideologia torna o espaço urbano, ou mesmo a região urbana, um ator político fortalecido, portador de diversos interesses de ordem política, econômica e cultural. Portanto, a cidade deve ser entendida como o elemento gestor da espacialidade, pois seus atores determinam, mediante os seus interesses, a organização e o desenvolvimento da sua estrutura urbana.

Para que se chegue a esse ponto, Souza (2005) defende a ação autônoma e organizada dos atores sociais no interior da cidade, nos enfrentamentos dos seus problemas localizados, respaldando na articulação política das intervenções em todo o espaço urbano. Diante dessa consideração, a articulação política no meio urbano está submetida as articulações entre as escalas e os atores sociais.

Mas no Brasil, dependendo da região, configuram-se cidades com as mais distintas funções. A problemática metropolitana apresentada por Souza (2005) das cidades do Rio de Janeiro e de São Paulo, por exemplo, não necessariamente é a mesma problemática urbana da Região Metropolitana de Goiânia (RMG), tomando o Estado de Goiás como exemplo. No Rio de Janeiro, Souza (2005) destaca o fator da ingovernabilidade urbana.

No caso específico da RMG a problemática pode estar ligada, por exemplo, à falta de moradias, aos vazios urbanos, à segregação espacial, à fragmentação do tecido espacial, e à fragilidade econômica dos municípios que estão em volta de Goiânia. Ou seja, a problemática urbana da metrópole Goiânia tem forte ligação com a questão da escala, sintetizando-se no espraiamento do tecido urbano e nos problemas advindos dessa configuração espacial fragmentada. Nesse sentido, é de fundamental importância recorrer a uma breve discussão acerca das múltiplas escalas de análise contidas no espaço urbano. 


\section{As escalas de análise do espaço urbano: 0 espaço intraurbano e intra-metropolitano}

Reconhecer que há uma cisão entre os estudos urbanos, no que se refere ao uso das escalas, é importante no momento. Visualizar a necessidade de se escolher uma determinada escala de análise, não negligenciando a possibilidade de se transitar por outros recortes espaciais, também é relevante, principalmente, partindo do pressuposto de que é relevante discutir as transformações existentes na escala intra-metropolitana e na escala intraurbana.

As cidades da América Latina e Ásia são marcadas por extensas áreas urbanas, sustentadas por acirradas discrepâncias socioeconômicas. Essa condição espacial encontrada, principalmente (não exclusivamente), em cidades latino-americanas promove a necessidade de se interpretar os espaços urbanos através de múltiplas escalas.

É comum aos analistas urbanos apresentarem o problema da expansão urbana generalizada e dar denominações, no interesse de classificar as diferentes formas e funções desses aglomerados urbanos, como no caso das nomeações: cidades mundiais, megacidades, metrópoles, megalópoles, metápolis, cidade-região, entre outras. Essas denominações demonstram o quanto as cidades apresentam possibilidades de interpretações que utilizem o recurso de diversas escalas. Considerar as várias escalas de análise, além de classificar e dar nomes às cidades tem como proposta reconhecer as múltiplas dimensões espaciais contidas na cidade.

A escala geográfica não é somente a escala métrica ou cartográfica, conforme destaca Castro (1995). Nela está contida a dimensão espacial, social e histórica. Desse modo, os analistas do espaço urbano desenvolvem estudos que estão ligados a morfologia urbana, outros levam em conta a função, os processos e as interações socioespaciais. É importante reconhecer que a escolha de uma determinada escala de análise possibilita maior precisão na investigação proposta.

Nesse sentido, pode-se analisar os núcleos urbanos como um todo, considerando os aglomerados urbanos, as conurbações, as interações intermunicipais etc. Por outro lado, também é relevante considerar as peculiaridades intraurbanas, as diferenciações internas das cidades. A cidade precisa ser interpretada em conjunto, com clareza nos detalhes, e ao mesmo tempo, com precisão nas considerações mais gerais. Dessa forma, Davidovich (2003, p. 3) mostra que o dinamismo econômico e a concentração populacional dão diferentes dimensões às cidades atuais. 
A designação de metrópole tem permanecido, devido, em grande parte, ao valor emblemático que adquiriu, seja como representação de problemáticas econômicas e sociais, seja pelas posições mais elevadas na hierarquia urbana, seja pela dominação política e polarização que exerce sobre lugares de um dado território. É preciso, contudo, considerar que tal designação genérica não corresponde à um tipo ideal, já que a metrópole é um fenômeno plural, que apresenta diferentes dimensões e formas de concentração.

No caso específico do Brasil, metrópoles como Rio de Janeiro e São Paulo não devem ser comparadas, indiscriminadamente, com cidades de tamanho médio, caso específico de Anápolis. Do mesmo modo, no interior de uma Região Metropolitana (RM) encontram-se diferenciações entre a cidade pólo e os municípios periféricos, sendo fundamental definir parâmetros de investigação diferenciados, principalmente, partindo da noção de que nas RMs do Brasil, atualmente, os municípios periféricos crescem mais que os municípios pólos. Os municípios polarizadores apresentam diferenças significativas dos municípios periféricos, principalmente no que se refere ao grau de desenvolvimento humano, dinamização econômica, concentração de serviços de consumo coletivos etc. Contraditoriamente, tem-se uma única cidade congregada em uma definição político-territorial, a Região Metropolitana, e ao mesmo tempo, duas (ou mais) dinâmicas urbanas distintas, grosso modo o centro e a periferia. ${ }^{1}$

O quadro urbano que se edificou na RMG indica a necessidade de se avaliar as múltiplas escalas de interpretação. Qual seria a escala de análise mais apropriada? A resposta está no que se propôs analisar. Ou seja, verificar o destaque da RMG com relação à urbanização do Estado de Goiás delineia uma lógica interpretativa. Debruçar sobre a tessitura intra-metropolitana e a articulação existente entre os municípios marginais da RMG e o município pólo envolve o tema da mobilidade e da segregação. No caso específico desse trabalho, para responder seu objetivo proposto, tem como escolha de escala a intra-urbana e a intra-metropolitana, pois estas são suficientes para explicar com afinco as transformações que vêm ocorrendo no espaço urbano. As demais escalas se encontram em segundo plano, mas não são descartadas.

A literatura recente sobre Goiânia dedicou boa parte das suas interpretações à escala intraurbana e ao tema cidade, caso dos trabalhos apresentados por Cavalcanti (2001), Vaz (2002), Paula (2003), Cavalcanti e Paula (2007), entre outros. Nesses trabalhos, de uma forma ou de outra, os autores dedicaram-se a temas como: novas centralidades, policentralização, "decadência” do centro tradicional, formação de novos centros abastados e a se- 
gregação sócio-espacial. ${ }^{2}$ Outros trabalhos relevantes elucidaram o tema da metropolização de Goiânia, caso de Morais (1991), Chaveiro (2001), Arrais (2004, 2007), Moysés (2004, 2005), entre outros. Essa gama de temas urbanos da literatura goiana demonstra a relevância de não existir o excesso de trabalhos que abordam uma única escala. O desafio no momento atual é debruçar sobre essa "metrópole em travessia”, conforme a expressão cunhada por Chaveiro $(2001,2004)$, não somente atomizando-a, ou discriminando-a, ou seja, isolando-a dos nódulos urbanos que formam sua hinterlândia conurbada.

Por outro lado, existem, grosso modo, duas linhas teóricas e metodológicas de análise e de intervenção da cidade, carregadas por duas escalas distintas: a urbano-regional e a intraurbana. Elas partem desde a ecologia urbana (GEDDES, 1994; BOGUE, 1976; GILBERT, 1991 entre outros), ou do neo-positivismo quantitativo, ou das linhas de cunho crítico, exemplo de Munford (1982) e o caso do marxismo estruturalista de Castells (2000), com o clássico A Questão Urbana, que contraria as teses lefrebvrevianas, pois chama a atenção para o papel do estado e do consumo coletivo como veio estruturante do urbano, sendo o espaço um mero receptáculo da sociedade. Lefebvre, com a Revolução Urbana (1999), A Cidade do Capital (1999b) e Direito à Cidade (1991), entre outros, apresenta uma base teórica indispensável para a compreensão da cidade pela perspectiva marxista menos ortodoxa, embebida pela lógica da produção social do espaço urbano.

Com a mesma concepção epistemológica do marxismo, apesar de sutis críticas e com consideradas diferenças de Lefebvre, Harvey (1980) buscou sintetizar uma teoria revolucionária da geografia, construindo uma visão singular sobre o uso do solo urbano, o planejamento urbano, e a perspectiva de integração econômica da cidade. Na contramão dessas teorizações estruturantes do materialismo histórico dialético, a perspectiva crítica humanista de Tuan (1980) enfatiza o teor essencialista do espaço vivido, influenciando uma geração caleidoscópica que estudam a cidade, tendo como base filosófica a fenomenologia e o existencialismo. Outra perspectiva teórica é a abordada por Soja (1993). Este autor desenvolve críticas ao posicionamento do marxismo com relação a sua negligência ao espaço, buscando assim a reafirmação crítica da teoria espacial, incluindo no clichê pós-moderno a dimensão espacial, temporal e social, construindo a proposta de um materialismo histórico e geográfico. Outras perspectivas teóricas como o pós-estruturalismo e a da autonomia se dedicaram aos temas urbanos. O trabalho de Souza (2005) merece destaque, pois geografiza com 
autoridade a perspectiva da autonomia defendida pelo filósofo Castoriadis (1982 e 1987).

Ao discutir as distintas escalas do espaço urbano, Villaça (1998), em Espaço Intra-urbano do Brasil, chamou a atenção para a questão semântica da escala intraurbana. Afirmou-se que é tautologia usar o termo intraurbano, pois ele é sinônimo de urbano. Para o citado autor, o modismo dos termos urbano, estruturação urbana e reestruturação urbana trazia status para os urbanistas regionais que os utilizavam, causando confusão entre os analistas que enfocavam o interior da cidade. Confusões como: Quem trata da morfologia interna da cidade (sua endogenia), ou o que lhe promove? Quem trata da exogenia urbana, e o que lhe motiva? Nessa perspectiva, o autor, estabeleceu uma cisão entre a análise interna e externa das cidades brasileiras, e ainda foi mais longe, destacou que a dinâmica interna das cidades nacionais e talvez latino-americanas é diferente da européia e norteamericana, principalmente da estadunidense.

Villaça (1998, p. 20) destaca que o espaço intraurbano se conduz pela localização. Ele é estruturado pelo "deslocamento do ser humano, seja enquanto portador da mercadoria força de trabalho - como no deslocamento casa/trabalho -, seja enquanto consumidor - reprodução da força de trabalho, deslocamento casa-compras, casa-lazer, escola etc.” A localização determina a mobilidade, a coesão e a segregação das classes sociais, que por sua vez reestrutura o espaço interno das cidades. Villaça (1998, p. 22) completa afirmando que, "o urbano passa então a ser definido em termos dos efeitos particulares da intensidade das interações entre o social e o espacial, provocadas pela forma específica de articulação espacial da produção, da circulação do consumo, na formação social”. Este autor percorre os ensinamentos de Castells (2000) de que a cidade é produto do consumo coletivo.

O espaço Intraurbano passa a significar mais do que uma escala de análise, funcionando como um conceito de análise urbana. Nessa lógica, Spósito (1998) propõe o discernimento entre a centralidade intraurbana da centralidade regional. Para a referida autora, centralidade intraurbana envolve uma reflexão sobre as novas formas comerciais da cidade, do deslocamento dos citadinos para o uso da mesma e para a diversificação e polarização interna dos nódulos centrais. Por sua vez, a centralização urbana estaria calcada na polarização da metrópole e seu raio de ação, na sua região, pelo veio produtivo e funcional. Por sua vez, a escala intraurbana ganhou força, principalmente, a partir do momento em que Villaça (1998) afirmou ser essa escala nova e pouco explorada. 
Quadro 1: Principais características da escala urbano-regional e intraurbana.

\begin{tabular}{|c|c|}
\hline Escala urbano-regional & Escala intra-urbana \\
\hline $\begin{array}{l}\text { - No espaço urbano-regional os deslocamentos de } \\
\text { mercadorias, energia e comunicação têm poder } \\
\text { estruturante; }\end{array}$ & $\begin{array}{l}\text { - No espaço intraurbano o que impacta na sua es- } \\
\text { trutura ou reestruturação são os transportes e a } \\
\text { mobilidade de pessoas, enquanto portadores de } \\
\text { mercadoria força de trabalho ou como consumi- } \\
\text { dores do espaço; }\end{array}$ \\
\hline $\begin{array}{l}\text { - Na escala urbano-regional os modelos de desen- } \\
\text { volvimento são fundamentais e determinantes } \\
\text { para a articulação da organização espacial; }\end{array}$ & $\begin{array}{l}\text { - Na escala intraurbana os modelos de desenvol- } \\
\text { vimento e intervenção regional não influem de- } \\
\text { cisivamente na sua estrutura; }\end{array}$ \\
\hline $\begin{array}{l}\text { - Os temas da escala urbano-regional enfocam a } \\
\text { reestruturação produtiva, o mundo do trabalho, } \\
\text { a desconcentração industrial, etc. }\end{array}$ & $\begin{array}{l}\text { - Os temas da escala intraurbana se dedicam a } \\
\text { explicar a descentralização, a polinucleação, os } \\
\text { subcentros, a reestruturação intra-urbana, etc; }\end{array}$ \\
\hline
\end{tabular}

Fonte: Adaptado de: VILLAÇA, F. Espaço intra urbano no Brasil. São Paulo, Nobel: 1998.

Organizado por: José Vandério Cirqueira Pinto, 2010.

Contrariando a perspectiva de análise interna das cidades, Ribeiro (2004, p. 9) afirmou que "A literatura acadêmica sobre os 'estudos urbanos' vem sendo marcada por um olhar excessivamente intra-urbano, setorial e localista." Para este autor, o tema da metrópole vem sendo negligenciado e merece maior atenção devido à ebulição de multiplicidades espaciais das mesmas. Para essa compreensão o intraurbano não consegue sozinho congregar a leitura da fragmentação metropolitana dos processos de globalização e das mudanças do modo de produção, que acarretam crises sociais, ingovernabilidade urbana e incisivas transformações da cidade. Soja (1993), pela mesma ótica, seguindo os ensinamentos de Lefebvre, chama a atenção para a transformação do urbano como produto dos rearranjos macrossistêmicos do capitalismo, da sociedade da informação, do consumo e do trabalho, existindo não uma cisão, mas uma ligação entre os fluxos de produção e a alteração da estrutura socioespacial da cidade. A argumentação de Soja (1993, p. 126) se desenvolve da seguinte maneira:

Como resultado de outra rodada de reestruturação, o capital financeiro tornouse ainda mais significativo na modelagem do espaço urbano em conjunção não apenas com o capital industrial, mas também, cada vez mais, com o outro agente de regulação e de reestruturação espacial, o Estado. Essa coalizão entre o capital e o Estado funcionou eficazmente, replanejando a cidade como uma máquina de consumo duráveis. O crescimento dessa "fronteira de grama" das casas suburbanas também intensificou a segregação residencial, a fragmentação social e a segmentação ocupacional da classe trabalhadora. 
De uma forma ou de outra, Villaça (1998) acerta em didatizar o enfrentamento da análise urbana. Mostrou com clareza e contundência dois eixos de transformação da cidade. Porém, atomizar a investigação do espaço geográfico é desconectar suas múltiplas ações sociais produtivas e reprodutivas. Esse erro se materializa quando se trata do centro de Goiânia, por exemplo, sem verificar sua interação com a RMG.

Na geografia urbana e no urbanismo, conforme mostrou Geddes (1994) no pioneiro estudo sobre a conurbação e as cidades-regiões, Cidades em Evolução, as cidades não são mais unas, se entrelaçaram formandose cidades-regiões, densificando suas estruturas, tornando complexos os elementos que incidem sobre elas. Há quem afirme, sustentado nessa prerrogativa, que hoje existem "cidades-regiões globais como motores da economia global” (SCHOTT et. all. 2001 p. 14). Outros como Johnson (1974), Beajeu-Garnier (1980), Harvey (1980), Gottdiener (1993) etc. traçam o mesmo caminho, interpretando a cidade por múltiplas escalas. Recentemente, Souza (2005) vem contribuindo com temas urbanos presentes na atualidade brasileira. Com veemência, este autor transgride as perspectivas tradicionais do marxismo, pois estas tratam a cidade como um fatalismo economicista e mecânico. $\mathrm{O}$ autor citado busca olhar a cidade pelas suas múltiplas escalas e perspectivas, tendo como pano de fundo a autonomia dos sujeitos. Apesar de cético na interpretação, mostra-se atento nas propostas de mudança, destacando o caminho do desenvolvimento, real e não ideológico.

Com relação à noção de cidade-região, vale destacar o excessivo uso dessa concepção, presente nas análises das cidades, sustentado por um modismo científico, o mesmo modismo criticado por Villaça (1998) ao se tratar da escala urbano-regional. É desenvolvida também uma indefinição do que seria realmente uma cidade-região, qual a sua diferença da Região Metropolitana, da Megalópole etc. É necessário considerar inicialmente a cidaderegião pelo viés da escala geográfica, ou seja, sua expansão e dinamismo urbano, sua integração e diversificação econômica, não deixando de considerar o momento atual do capitalismo flexível. Portanto, o uso do termo cidade-região dado por Geddes (1994) no início do século XX, quando analisou as conurbações britânicas, é muito mais atual e inteligível, expressa mais seu verdadeiro significado do que as rebuscadas denominações atuais, carregadas de muita consideração teórica e pouca significação prática. Com relação à perspectiva mais prática da escala urbana Klink (2001, p. 7) discute da seguinte forma: 
Entendemos as cidades-regiões como aquelas áreas metropolitanas com aproximadamente um milhão de habitantes, cuja delimitação administrativa e institucional nem sempre coincide com sua identidade política e econômica, e que estão inseridas nos processos globais de transformação socioeconômicas.

Não se limitando somente à escala da cidade-região, merece destacar que os processos de urbanização no mundo atual trazem à tona fortes desafios, que são capturados dependendo da escala de análise escolhida. Prender-se somente a uma única perspectiva é limitar as múltiplas dimensões do espaço urbano. ${ }^{3}$

\section{Conclusões}

Em síntese, tendo a pretensão de olhar paro o espaço urbano, em especial o da RMG, na tentativa de elucidar seu teor fragmentário, busca-se a escala mais relevante. A fragmentação e a mobilidade podem ser vistas pela escala intraurbana, caso das policentralidades da RMG, espectro da fragmentação do centro; caso dos condomínios horizontais fechados, ou enclaves fortificados, tomando a expressão de Caldeira (2003), que concentram em Goiânia, porém estão presentes em Aparecida de Goiânia, Senador Canedo, Trindade e Bela Vista de Goiás. Pode-se também atomizar cada município da RMG, escolher um e explicar fenômenos que protagonizam em toda a RMG, afirmando a lógica concentradora. Pode-se destacar fenômenos específicos de um dado município, elucidando que na RMG existem áreas especializadas, que fragmentam o bojo metropolitano, pois apresentam específicas funções. Por último, pode-se destacar a integração urbana que se edifica na RMG. Essa perspectiva mais generalizante chama a atenção para a problemática metropolitana de Goiás, destacando um novo paradigma de gestão urbana no Estado.

O não entendimento da escala de gestão urbana gera generalizações e, consequentemente insuficiências na intervenção dos problemas apresentados. No mundo atual, são comuns cidades com extensos tecidos urbanos, com densas massas populacionais, principalmente, naqueles países denominados de economia dependente. A RMG está inserida nesse quadro comum da maioria das metrópoles brasileiras. Saber como essa Região Metropolitana (RM) se coloca perante as outras RMs do país é passo necessário para que se discuta posteriormente sua organização interna. 


\section{Notas}

1 A título de exemplo, Arrais (2004) identifica três escalas de análise diferenciadas ao discorrer sua interpretação sobre Brasília. O citado autor defende que existe Brasília (o Plano Piloto), as Cidades Satélites e o Entorno de Brasília, ou seja, três lógicas de análise de uma mesma cidade.

2 Esses temas, vinham sendo discutidos com freqüência em países da América do Norte e Europa, e com menor intensidade, no Brasil, México, Argentina, África do Sul. O importante desses autores acima citados é que eles de forma inovadora discutiram com categoria e precisão abordagens precoces no Brasil e em Goiás.

3 Santos (1996) argumenta que a espacialidade contém o local e o geral, ou seja, nas partes estão contidas a totalidade. Para Grataloup (1991, p. 157) recortar é identificar o particular a partir do geral, sendo que o "território do geógrafo [...], deve ser limitado e recortado, para poder ser identificado, administrado, atribuído”. As múltiplas dimensões do espaço se interpõem nas horizontalidades e verticalidades destacadas por Santos (2002), sendo o espaço, um conjunto indissociável de sistemas de objetos e sistemas de ações. Fica evidente a indissociablidade da investigação espacial das múltiplas escalas. Por isso, tanto o intra-urbano como o urbano-regional não devem ser antagonizados, do contrário tornamse fraseologismos.

\section{Referências}

ARRAIS, T. P. A. Geografia contemporânea de Goiás. Goiânia: Vieira, 2004.

. A região como arena política. Goiânia: Vieira, 2007.

BEAUJEU-GARNIER, J. Geografia urbana. Lisboa: Fundação Calaste Gulbenkian, 1980.

BOUGUE, D. J. Essays in human ecology 1. Chicago: Community and Family Study Center University of Chicago, 1976.

CASTELLS, M. A questão urbana. Rio de Janeiro: Paz e Terra, 2000.

CASTORIADIS, C. A instituição imaginária da sociedade. Rio de Janeiro: Paz e Terra, 1982.

. As encruzilhadas do labirinto. v. II. Rio de Janeiro: Paz e Terra, 1987.

CASTRO, I. E. O problema da escala. In: CASTRO, I. E., GOMES, P. C. Da C., CORREA, R. L. (Org.) Geografia, conceitos e temas. Rio de Janeiro: Bertrand Brasil, 1995, p. 117 - 140.

CAVALCANTI, L. de. S. (Org.). Geografia da cidade: a produção do espaço urbano de Goiânia. Goiânia: Alternativa, 2001.

CAVAlCANTI, L. S., PAUlA, F. M. de A. (Org.) A cidade e seus lugares. Goiânia: Vieira, 2007.

CHAVEIRO, E. F. A urbanização do sertão goiano e a criação de Goiânia. In: GOMES, H. (Org.) O espaço goiano: abordagens geográficas. Goiânia: Associação dos Geógrafos Brasileiros, 2004. p. 93-144.

CHAVEIRO, E. F. Goiânia, uma metrópole em travessia. 2001. Tese (Doutorado em geografia). Universidade de São Paulo - USP: São Paulo, 2001. 
CLARK, D. Introdução à Geografia Urbana. São Paulo: DIFEL, 1985.

DAVIDOVICH, F. Regiões Metropolitanas no Brasil: referências para debate. In: Encontro Nacional da ANPUR, 10, 2003, Belo Horizonte. Anais... Belo Horizonte: UFMG, 2003.

GEDDES, P. Cidade em evolução. Campinas: Papirus, 1994.

GILBERT, O. L. The ecology of urban hatitats. London: Chapiman e Hall, 1991.

GOTTDIENER, M. A produção social do espaço urbano. São Paulo: EdUSP, 1993.

GRATALOUP, C. As regiões do tempo (extratos). In: Périodes: la construction du temps historique. Paris, 1991; p. 157-173.

HARVEY, D. A justiça social e a cidade. São Paulo: HUCITEC, 1980.

JOHNSON, J. H. Geografía urbana. Barcelona: Oikos-tau, 1974.

LEFEBVRE, H. A cidade do capital. Rio de Janeiro: DP\&A, 1999b.

O direito à cidade. São Paulo: Moraes, 1991.

. A revolução urbana. Belo Horizonte: Humanitas, 1999.

LEVY, J. Os novos espaços da mobilidade. In: GEOGRAFHIA. Revista de Pós-graduação em Geografia da UFF. Ano 3, n. 6. Niterói/RJ, 2002.

MORAES, S. O empreendedor imobiliário e o Estado: o processo de expansão de Goiânia em direção sul. (1975-1985). Brasília, 1991. Dissertação (Mestrado) - Universidade de Brasília, 1991.

MOYSÉS, A. (Coord.) Cidade, segregação urbana e planejamento. Goiânia: Ed. UCG, 2005.

. Goiânia, metrópole não planejada. Goiânia: Ed. UCG, 2004.

MUNFORD, L. A cidade na história: suas origens, transformações e perspectivas. São Paulo: Martins Fontes, 1982.

PAULA, F. M. de A. Descentralização e segregação sócio-espacial em Goiânia: uma análise das centralidades dos setores Bueno, Oeste e Marista. 2003. 202. f. Dissertação (Mestrado em Geografia) IESA, Universidade Federal de Goiás, Goiânia, 2003.

RIBEIRO, L. C. de. Q. (Org.) Metrópoles: entre a coesão e a fragmentação, a cooperação e o conflito. São Paulo: Editora da Fundação Perseu Abrano; Rio de Janeiro: FASE, 2004.

SANTOS, M. A natureza do espaço - Técnica e tempo. Razão e emoção. São Paulo: Ed. USP, 2002.

SANTOS, M. Por uma geografia nova. São Paulo: Hucitec, 1996.

SCOTT, J. A. et all. Cidades-regiões globais. Espaço \& Debates. Aliança e competição entre cidades. 41. Revista de estudos regionais e urbanos. São Paulo, Núcleo de Estudos Regionais e Urbanos, 1981. Ano XVII, 2001. p. 11-25.

SOJA, E. W. Geografias pós-modernas: a reafirmação do espaço na teoria social crítica. Rio de Janeiro: Zahar, 1993.

SOUZA, M. L. de. O desafio metropolitano: um estudo sobre a problemática sócio-espacial nas metrópoles brasileiras. 2. ed. Rio de Janeiro: Bertrand Brasil, 2005. 
SPOSITO, M. E. B. Gestão do território e as diferentes escalas da centralidade urbana. Território. Rio de Janeiro: UFRJ, ano III, n. jan./jun. 1998. p. 40-59.

TUAN, Y. Topofilia: um estudo da percepção, atitudes e valores do meio ambiente. São Paulo: Difel, 1980.

VAZ, M. D. A. C. Transformação do centro de Goiânia - renovação ou reestruturação? 2002. 269 f. Dissertação (Mestrado em Geografia). Instituto de Estudos Sócio-ambientais (IESA), Universidade Federal de Goiás (UFG), Goiânia, 2002.

VILLAÇA, F. Espaço intra-urbano no Brasil. São Paulo: Studio Nobel: FAPESP: Lincoln Institute, 1998.

José Vandério Cirqueira Pinto - Professor efetivo da Secretaria Municipal de Educação de Goiânia (SME) e professor da Faculdade Suldamérica.

Recebido para publicação em Setembro de 2009 Aceito para publicação em Dezembro de 2009 